technology markets," suggests the recent IEA Clean Energy Progress Report ${ }^{5}$. Then, as the costs of producing wind and solar power go up or down, the subsidies could be adjusted.

Policies could also select energy sources that may be more favourable in the face of rising oil prices. King suggests putting them through a kind of natural selection. "A good [renewable] would be able to grow and replicate itself on its own juice," he says. "If it's not good enough to produce more of itself, what is it good for?" Lindmayer, who pursued the solar breeder for more than a decade, would probably have agreed.

Mason Inman is a freelance science writer based in California, USA.

e-mail:masoninman@gmail.com

References

1. Dwyer, A., Gardner, G. \& Williams, T. Bulletin: June Quarter 2011 49-57 (Reserve Bank of Australia, 2011).

2. Fthenakis, V. et al. Update of PV Energy Payback Times and Life-Cycle Greenhouse Gas Emissions (24th European Photovoltaic Solar Energy Conference, 2009)
3. Hamilton, J. Historical Oil Shocks Working Paper 16790 (National Bureau of Economic Research, 2011); available via http://go.nature.com/FwMvct.

4. New Energy Finance Weathering the Storm (Bloomberg New Energy Finance, 2010)

5. International Energy Agency Clean Energy Progress Report (IEA, 2011).

6. International Energy Agency Medium-Term Oil and Gas Markets (IEA, 2011).

7. Available via http://go.nature.com/XUnDkm.

8. United Nations Environment Programme Global Trends in Renewable Energy Investment 2011 (UNEP, 2011)

Published online: 21 August 2011

\title{
SNAPSHOT
}

\section{Electric highway}

By the end of September, the UK will have the world's first national network of charging stations for plug-in electric vehicles. This infrastructure will enable electric vehicles to make longerdistance journeys, overcoming a major impediment to their popularity.

A charging post that can accommodate two vehicles at a time will be operational at each of 12 Welcome Break service stations scattered along the nation's major motorways by the end of summer, says Stuart Brennan, a spokesman for Ecotricity, the sustainable energy company, based in Stroud, that will be installing and maintaining the charging stations and supplying solarand wind-generated electricity to them. Within 18 months, the company will have installed a charging post at a further 15 highway service points nationwide, he says.

Drivers using the charging station's rapid recharge feature, running at 32 amps, will be able to top-up in 20 minutes and completely recharge in two hours; the slower, 13-amp power supply will take several hours to fully recharge. Ecotricity will provide its recharging for free.

There are at present about 2,000 pure electric vehicles in the UK, as well as a few hundred plug-in electric hybrids. But, although there are already around 400 charging points in cities around the country, more than half of these are concentrated in London. Charging stations in Ecotricity's new network will be located no more than 160 kilometres (100 miles) apart, which is within the range that a currentgeneration plug-in electric vehicle can travel on a single charge $-99.6 \%$
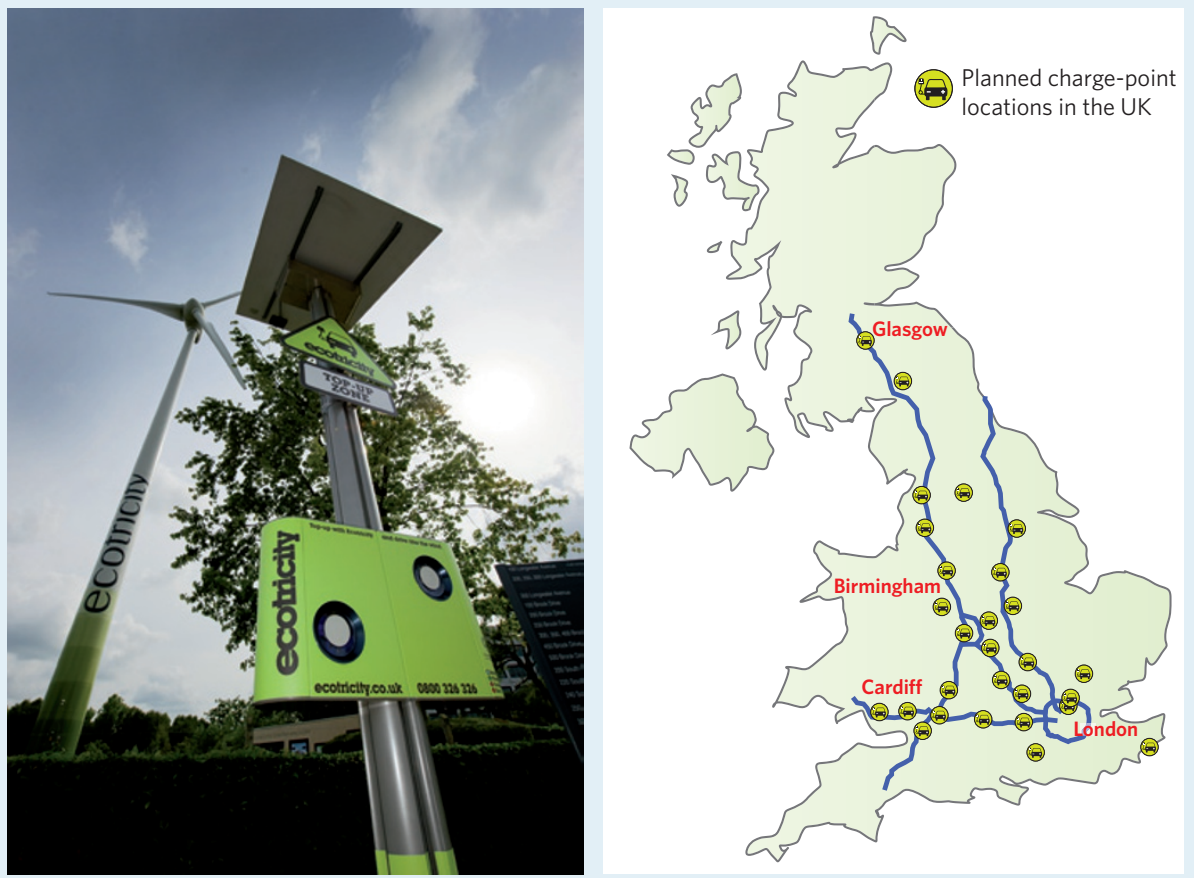

of British car journeys are less than 160 kilometres.

The nationwide network of charging stations should help alleviate drivers' 'range anxiety', which often restricts people to driving within their own city, and is one of the main psychological barriers for people who may want to buy a plug-in electric vehicle. "Our purpose is to help drive the acquisition of electric vehicles in the market," says Brennan.

Yet such range anxiety is often a matter of perception, says Shannon Arvizu, a Los Angeles-based sociologist and author of the forthcoming book The Plug-in Vehicle Network: Driving Change in the USAuto Industry. Indeed, she notes, early adopters of plug-in electric vehicles are often enthusiastic about their purchase and report that their travel plans are not hampered by the vehicle's range limitations.

Nevertheless, Arvizu adds, the convenience of being able to recharge both locally and along major highways will send a strong signal to members of the public that previously hadn't seriously considered purchasing an electric vehicle.

The UK Department for Transport estimates that by 2015 there will be tens of thousands of plug-in vehicles on the roads in the UK. 